\section{Spontaneous Rupture of Aortic Valve Cusp Attachment}

\section{British Medical fournal, 1970, 3, 206}

Rupture of the aortic valve is an uncommon occurrence and has been described as a consequence of strain or injury (Howard, 1928; Kissane et al., 1948) and as the result of septic endocarditis or syphilis (Carrol, 1951). It may also occur in a pre-existing fenestrated leaflet and in hypertension (Marcus et al., 1963), arachnodactyly (Bean and Mohaupt, 1952; McKusick, 1955), inherited disorder of connective tissue (Frieden et al., 1962), myxomatous transformation of the cusps (O'Brien et al., 1968), and aneurysm of the ascending aorta with cystic medionecrosis (Levy et al., 1963). Spontaneous rupture of a normal aortic valve with cystic medionecrosis but without Marfan's syndrome or other inherited disorder of connective tissue is extremely rare. We report such a case.

\section{CASE RePort}

A 43-year-old farmer was admitted to the Hippocration Hospital on 10 December, 1968. Twenty-five days earlier he was awakened by intense dyspnoea, palpitations, and a feeling of precordial pressure. With bed rest and the administration of digitalis and diuretics he gradually improved, and within a week the symptoms had disappeared. There was no history of previous heart disease.

On examination peripheral signs of aortic insufficiency were noted. There was no precordial thrill. A loud harsh early diastolic murmur was heard along the left sternal border, especially at the third and fourth intercostal spaces, and a mid-systolic murmur (II/VI). Both were conducted to the right. The aortic second sound was decreased. Blood pressure $140 / 60 \mathrm{~mm}$. $\mathrm{Hg}$ in both arms. Chest $x$-ray examination showed moderate cardiac enlargement with normal lung fields. Electrocardiogram showed atrial fibrillation and a widened QRS complex. S-T and T changes were present, but he was on digitalis.

Despite his good general condition the patient died suddenly of ventricular fibrillation $\mathbf{5 5}$ days after the onset of the disease.

Necropsy Findings:-The lungs, liver, spleen, kidneys, and abdomen showed no gross changes. The heart was enlarged, weighing $480 \mathrm{~g}$. The left ventricle was hypertrophied (the wall measured $2 \mathrm{~cm}$.) and slightly dilated. The common attachment of the posterior and right anterior aortic valve cusps to the aortic wall was longitudinally detached from the aortic wall over a distance of $1.3 \mathrm{~cm}$.

Histological Examination:-The detachment had occurred at the intima and inner layer of the media of the aorta. Section of the aorta showed a normal medial thickness. There were numerous small pools of mucoid material in which some fragments of elastic tissue were seen to be in a state of dissolution. The elastic tissue surrounding the mucoid pool was interrupted, and collagen and muscle elements were also destroyed in the areas of pooling. The elastic tissue away from the mucoid pools showed only slight fraying, and fragmentation was not observed. In one area the inner third of the media had been lifted up and the underlying space was filled with structureless material and cholesterol clefts. This had the appearance of a small intramural haemorrhage. There was no evidence of past or recent inflammation. The coronary arteries were normal. It was concluded that the changes were those of Erdheim's medionecrosis.

\section{COMMENT}

The finding of a diastolic murmur of aortic incompetence, sometimes associated with a thrill, and the sudden onset of symptoms of left ventricular failure are clinical characteristics of rupture of the aortic valve (Howard, 1928, O'Brien et al., 1968). The usual gross pathological pattern is rupture or perforation of one or two cusps (Carrol, 1951; Marcus et al., 1963) or tear or detachment of an aortic cusp from the commissure to the adjacent aortic cusp (Frieden et al., 1962; O'Brien et al., 1968). In the reported cases of spontaneous rupture of the aortic valve with cystic medionecrosis of the aorta or myxomatous transformation of the cusps there also coexisted manifestations of arachnodactyly or other inherited disorder of connective tissue (McKusick, 1955; Frieden et al., 1962) or some other disorder of the circulatory system (Levy et al., 1963). In the present case the detachment of the common attachment to the aortic wall of the right and posterior cusps in an otherwise normal aortic valve resulted in a prolapse of the cusps, producing severe aortic incompetence. The histological appearances suggested Erdheim's medionecrosis, but clinical manifestations or stigmata of Marfan's syndrome or other related connective tissue disorder were not present.

We have found in the literature only one similar case (Hays and Boggan, 1955). Howard (1928) reported a case similar to the one described here, but cystic medionecrosis was not referred to, possibly because it had not then been described. Injury to the aortic valve cusps and wall of the ascending aorta may be the only manifestation of Marfan's syndrome (Read et al., 1965; Wendt et al., 1965). The normal thickness of the media and the absence of fragmentation of the elastic tissue away from the mucoid pools as well as absence of all other stigmata ruled out the diagnosis of Marfan's disease in the present patient.

We wish to thank Dr. E. G. J. Olsen, of the department of pathology, Royal Postgraduate Medical School, London, who kindly made the histological report in this case.

D. Avgoustakis, M.D., Assistant Professor of Cardiology.

D. Athanassiadis, M.D. Lecturer in Cardiology. P. Toutouzas, M.D., Lecturer in Cardiology.

University of Athens Medical School, Hippocration Hospital, Athens.

REFERENCES

Bean, W. B., and Mohaupt, F. X. (1952). Fournal of the American Medical Association, 150, 92.

Carrol, D. (1951). Bulletin of the fohns Hopkins Hospital, 89, 309.

Frieden, J., Hurwitt, E. S., and Leader, E. (1962). American fournal of Medicine, 33, 615.

Hays, F. B., and Boggan, W. H. (1955). Annals of Internal Medicine, 43, 1107 .

Howard, C. P. (1928). Canadian Medical Association, 19, 12.

Kissane, R. W., Koons, R. A., and Clark, T. E. (1948). American

Fournal of Medicine, 4, 606 . Circulation, 27, 422 .

McKusick, V. A. (1955). Circulation, 11, 321.

Marcus, F. I., Ronan, J., Misanik, L. F., and Ewy, G. A. (1963). American Heart fournal, 66, 675.

O'Brien, K. P., Hitchcock, G. C., Barratt-Boyes, B. G., and Lowe, J. B., (1968). Circulation, 37, 273.

Read, R. C., Thal, A. P., and Wendt, V. E. (1965). Circulation, 32, 897. Wendt, v. E., Keech M. K. and Read, R. C. (1965). Circulation, 32, Suppi. No. 2, p. 218. 